\title{
Pelatihan Penulisan Buku dan Nama Samaran
}

\author{
Tomy Michael ${ }^{1)}$ \\ ${ }^{1}$ Fakultas Hukum, Universitas 17 Agustus 1945 Surabaya \\ 1tomy@untag-sby.ac.id
}

\begin{abstract}
The pseudonym given by Law No. 3-2017 will present a dilemma for lecturers in producing scientific books obtained at the National Library. Activities carried out with careful planning, activities carried out and the results of discussions about what will be written in books and popular articles that can be written by the participants. Training activities essentially provide an understanding of the rights and obligations of special authors in pseudonyms. Popular themes for lecturers with ISI, ASBI and Popular Article themes.
\end{abstract}

Keywords: pseudonym, book, obligation

\section{Pendahuluan}

Menulis dan membaca adalah dua keterampilan berbahasa yang tidak dapat dipisahkan. Menulis dan membaca merupakan aktivitas berbahasa ragam tulis. Menulis adalah kegiatan mengungkapkan atau menyampaikan gagasan, sedangkan membaca adalah keterampilan memahami tulisan secara bermakna. Seseorang mampu menulis setelah membaca banyak karya/tulisan orang lain (Sobari, 2018). Selain itu menulis juga membutuhkan keterampilan untuk mengalirkan informasi atau pesan dengan tujuan untuk membantu menyelesaikan permasalahan manusia agar tercapai tujuan komunikasi (Setiawan, 2017).

Di dalam perkembangannya, kemudahan itu, menjadi pertentangan saat ini terkait wujud pertanggungjawaban dalam membuat hasil karya khususnya buku. Mengacu pada Pasal 3 Undang-Undang Republik Indonesia Nomor 3 Tahun 2017 tentang Sistem Perbukuan (UU No. 3-2017), penyelenggaraan sistem perbukuan berasaskan kebinekaan, kebangsaan, kebersamaan, profesionalisme, keterpaduan, kenusantaraan, keadilan dan partisipasi masyarakat. Dalam perspektif ini, buku salah satu sarana luaran dalam mencapai identitas sebagai dosen yang mengacu pada Berdasarkan Pasal 1 Undang-Undang Nomor 12 Tahun 2012 tentang Pendidikan Tinggi (UU No. 12-2012), seorang dosen memiliki kewajiban untuk melaksanakan tridarma perguruan tinggi yaitu, pendidikan/pengajaran, penelitian, dan pengabdian kepada masyarakat. Dalam pelaksanaan tridarma perguruan tinggi, penelitian memiliki peran yang cukup penting bahkan menjadi salah satu indikator dalam penetapan angka kredit seorang fungsional dosen. Sebagai bentuk pengembangan ilmu pengetahuan, suatu hasil penelitian perlu dituangkan ke dalam sebuah tulisan.

Pada saat asas ini dibenturkan dengan Pasal 14 UU No. 3-2017 dimana negara mengakui keberadaan nama samaran yang sejajar dengan nama asli dalam naskah buku. Pemahaman akan nama samaran menjadi latar belakang adanya pelatihan Coaching "Menulis Buku dan Hak Istimewanya" karena kurangnya pengetahuan akan nama samaran sehingga tidak memunculkan kebaruan berpikir bagi calon penulis buku. Hal yang mendukung lainnya yaitu adanya Covid19 yang menjadikan para dosen untuk tetap aktif dalam melakukan penulisan buku.

Di dalam coaching ini, menulis saling berkaitan satu sama lainnya. Unsur-unsur dalam menulis minimal mencapai empat aspek, yaitu (1) aspek gagasan yang akan disampaikan yang berupa 
topik masalah, (2) aspek tulisan yang berbentuk jenis karangan, sebagai gaya cara menulis karangan narasi, deskripsi, argumentasi, persuasi, atau eksposisi agar pembaca dapat mencerna tulisannya, (3) aspek keterpaduan antarparagraf agar tidak tumpang tindih pembahasannya, dan (4) aspek bahasa memilih diksi yang tepat dan gaya bahasa (Munirah, 2015). Ketika adanya gagasan dalam menulis sudah muncul maka secara tidak langsung akan menumbuhkan minat menulis bagi dosen menggunakan nama samaran namun harus memperhatikan Pasal 14 huruf b UU No. 3-2017 yaitu penulis wajib mempertanggungjawabkan karya yang ditulisnya. Bentuk pertanggungjawaban ini tidak sekadar adanya surat perjanjian kerjasama misalnya namun seluruh aspek menjadi perhatian yang penting termasuk desain sampul.

\section{Metode}

Metode pelaksanaan kegiatan pengabdian kepada masyarakat ini dibagi menjadi beberapa tahap. Tahap pertama yaitu tahap perencanaan. Pada tahap ini, pihak penyelenggara melakukan diskusi dan adanya identifikasi masalah sesuai fakta di Unievrsitas Agung Podomoro. Dengan cara demikian penyelesaian problem secara ilmiah akan tujuan yang dicapai serta luaran yang ingin dicapai dalam Coaching (Suci, 2017). Kegiatan menggunakan aplikasi zoom dan bertujuan untuk merencanakan dan persiapan materi dengan diskusi terbatas sebelum dimulai kemudian mendiskusikan luaran yang ingin dicapai.

Tahap kedua dalam Coaching ini yaitu pelaksanaan kegiatan. Kegiatan ini dilaksanakan dalam bentuk penyampaian materi oleh salah satu anggota tim. Adapun materi-materi yang disampaikan yaitu "Isi, ASBI Dan Artikel Populer". Kegiatan terakhir dalam Coaching yaitu adanya hasil berupa kerangka berpikir yang akan dituliskan dalam buku serta artikel populer bagaimanakah yang tepat diulis oleh para peserta.

Untuk mengetahui bagaimana kerangka berpikir yang dikehendaki yaitu dengan menampilkan buku yang telah terbit dan adanya sesi tanya jawabn secara daring dengan peserta. Terdapat target yang ingin dicapai dalam Coaching adalah peserta dapat memiliki semangat yang tinggi dengan diakuinya nama samaran dalam menulis buku yang berupa hasil penelitian, pengabdian kepada masyarakat ataupun artikel yang sifatnya konseptual. Artikel tersebut nantinya akan diterbitkan oleh Penerbit R.A.De.Rozarie dalam wujud buku referensi.

\section{Hasil dan Pembahasan}

Kegaiatan Coaching dilakukan pada 30 Juni 2020 Pukul 14.00 WIB via Zoom, dengan Keynote Speaker Ketua IKAPI Jawa Timur Fatkul Anam serta dibawakan oleh Fajar Sugianto membahas tentang "Lanskap Menulis Buku Ilmiah dan Pemilihan Tema" dan dibawakan oleh Tomy Michael membahas tentang "Isi, ASBI Dan Artikel Populer". Dipandu oleh Jennifer Laura Bachsin. Kegiatan ini merupakan rangkaian dengan FH Universitas 17 Agustus 1945 Surabaya, IKAPI, R.A.De.Rozarie dan Universitas Agung Podomoro via Zoom dengan jumlah peserta sebanyak 20 orang dosen.

Pemaparan awal dilakukan dengan mengulas isi buku sebenarnya. Adakalnya buku dipahami sebagai rangkaian tulisan yang sifatnya kaku namun tidak memperhatikan estetika. Di dalam paparan, isi buku yang paling utama adalah sejauh mana penulis bertanggung jawab akan karyanya. Karena dalam konteks penelitian ilmiah, muncul keinginan di kalangan para ilmuwan agar kontrol eksternal seperti yang dilakukan komisi etika penelitian harus dibatasi bahkan dihilangkan (Jena, 2014). Tentu saja hal ini menjadi awal kesulitan yang harus dilewati. Dalam menulis isi membuat kerangka buku adalah hal yang penting dan adanya daya imajinasi yang tinggi mengelola kata menjadi suatu hal yang harus dipahami oleh dosen. 
Khusus dalam hal ini, fokus kegiatan berkutat pada karya hukum yang didalam naskah buku terkendala hasil plagiasi tinggi karena adanya pengutipan pasal dalam suatu perundangundangan. Ketidakmampuan dalam melakukan parafrase (Jupriono et al., 2009) merupakan kelemahan dalam penstudi hukum. Ilmu hukum mempunyai karakteristik sebagai ilmu yang bersifat preskriptif dan terapan. Sebagai ilmu yang bersifat preskriptif, ilmu hukum mempelajari tujuan hukum, nilai-nilai keadilan, validitas aturan hukum, konsep-konsep hukum, dan norma-norma hukum. Sedangkan sebagai ilmu yang terapan ilmu hukum menetapkan standar prosedur, ketentuan-ketentuan, rambu-rambu dalam melaksanakan aturan hukum (Michael, 2018). Kekakuan ini mengakibatkan menulis buku menghasilkan hasil plagiasi yang tinggi, penyebab secara lengkap yaitu menyalin satu artikel penuh tanpa melakukan pembaharuan; menyalin sekitar $75 \%$ artikel; menyalin beberapa bagian dari artikel seperti kalimat, paragraf atau illustrasi tanpa menyebutkan sumber rujukannya; menyalin parafrase dari paragraf (dengan mengubah beberapa kata atau menata ulang urutan kalimat asli); dan menyalin sebagian besar artikel tanpa memberikan penggambaran yang jelas tentang siapa yang melakukan atau menulis apa (Santoso, 2015).

Setelah adanya pemahaman akan parafrase maka Coaching beralih akan bolehnya nama samaran bagi penulis. Namun sifat legal ini menjadikan permasalahan ketika naskah telah selesai guna ke tahap pengurusan Angka Standar Buku Internasional (ASBI) ke Perpustakaan Nasional Republik Indonesia. Di dalam pengurusan ASBI wajib menyertakan surat permohonan melalui penerbit buku dan didalamnya tercantum identitas buku yaitu sampul, judul, daftar isi, jumlah halaman, tahun terbitan dan wujud cetakan apakah berupa cetak atau elektronik. Ketika nama asamaran dimasukkan dalam surat permohonan maka penerbit harus dapat mempertanggungjawabakan perbuatannya yaitu dengan memberikan surat pernyataan kepada calon penulis namun hal ini sesuai yang dipaparkan oleh R.A.De.Rozarie tidak bisa dilakukan karena nantinya buku karya doen akan menjadi bagian Laporan Beban Kerja Dosen atau Laporan Lerja Dosen. Tentu saja penggunaan nama samaran menjadikan buku tidak legal. Mengacu pada teori utilitarisme atau teori konsekuensialisme yang dibahas secara mendalam dan terstruktur oleh Jeremy Bentham maka sebetulnya penggunaan nama samaran hanyalah artifisial untuk menghasilkan penulis.

Manfaat dari nama samaran menjadi penting di era Covid-19 karena dengan adanya gejolak, baik dalam bidang ekonomi, sosial, politik, budaya dan hukum. Oleh karena itu untuk membantu masyarakat dalam memecahkan sebagian dari kekecewaannya dibutuhkan rujukanrujukan yang nantinya akan dapat diangkat sebagai pedoman jika perlu dan dapat berfaedah untuk mengatasi kebuntuan tersebut (Subagiyo, 1999). Fasilitas nama samaran seharusnya tidak digunakan oleh dosen karena ketika buku telah terbit akan ada banyak hal yang mengikutinya seperti adanya pelaporan yang akan tersitasi di Sinta, adanya pengecekan nama buku di lama Perpusnas hingga pengenalan hasil pemikiran yang sesuai UU No. 12-2012.

Dalam pelatihan, pengubahan paradigma akan nama samaran menjadi hal yang mudah ketika adanya pengecekan dari lembaga penelitian dimana dosen tersebut bekerja sehingga hasil karya itu bukan sekadar tulisan melainkan adanya kebaruan yang ditawarkan dan kesesuaian dengan ilmu hukum yang diminati bahwa:

"Based on the research findings and discussion, it can be concluded, first, science law (jurisprudence) and all sub-study with him in a large family study of the law, no matter how controversial as as a discipline independent and peculiar (sui generis), part from the humanities and social sciences, as well as natural science (exact) and social sciences 
which has had an undeniable place in the branches of science (Sonata, 2015)"

Tahapan berikutnya yaitu proses pengurusan ASBI yang bisa terkendala akan hal yang dilakukan setelah ASBI diberikan. Perpusna memberikan waktu terbatas bagi penulis untuk mengimrimkan bukti cetaknya dan seringkali buku cetak tidak diberikan lagi kepada Perpusnas sebanyak dua eksemplar dan perpusda dalam hal ini Kota Surabaya sebanyak satu eksemplar. Ketika ASBi diperoleh maka buku sudah layak untuk disebarluaskan akrena telah melalui tahapan akhir dari pihak penebrit dan sebetulnya terdapat dua perjanjian yaitu lepas dalam hal inni tanggung jawab penulis secara utuh atau sebagian dimana adanya pembagian royalti atau alienasi hak cipta kepada penerbit. Adanya ASBI juga mendorong buku dapat diterima secara internasional karena adanya fasilitas pengecekan di https://isbn.perpusnas.go.id/Account/SearchBuku yang mana nantinya akan masuk ke dalam profil Sinta penulis. Ketika nama samaran digunakan maka buku tidak akan terindeks dalam profil Sinta penulis yang berprofesi sebagai dosen. Untuk bisa terindeks ada bagian yang muncul dalam buku seperti persiapan, tabulasi, penerapan data, penyajian data dan penarikan simpulan (RAHYUDI et al., 2019).

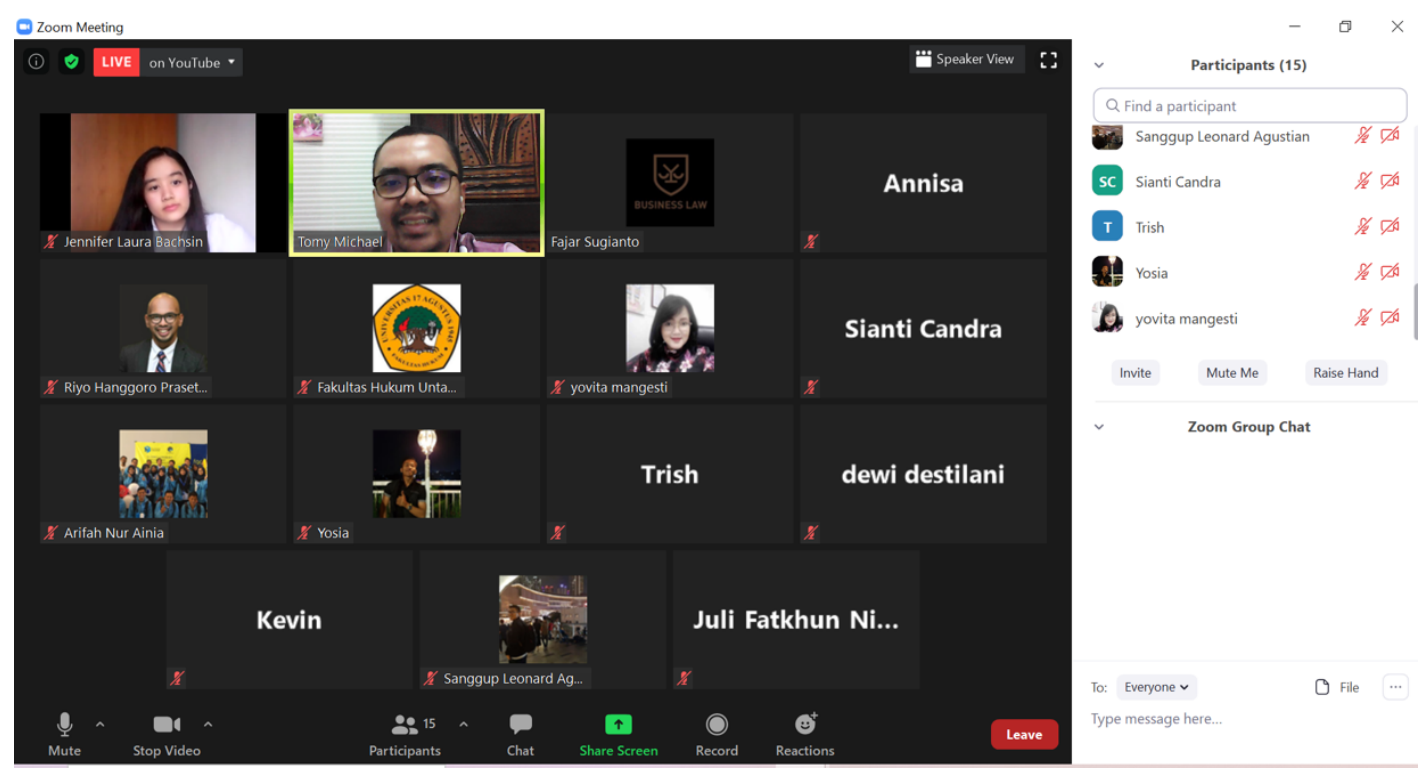

Gambar 1. Coaching dalam sesi tanya jawab ASBI

\section{Kesimpulan}

Kegiatan Coaching secara esensi memberikan pemahaman akan hak dan kewajiban penulis khususnya dalam nama samaran. Pemahaman ini tertuang yang ditujukan bagi dosen dengan menggunakan tema ISI, ASBI dan Artikel Populer.

Kegiatan Coaching ini dilakukan dalam keterbatasan waktu secara virtual namun setelahnya adanya diskusi lanjutan secara grup WA sehingga akan menghasilkan luaran berupa buku referensi.

\section{Referensi}

Jena, Y. (2014). Memperkuat Tanggung jawab Moral Peneliti. RESPONS.

Jupriono, D., Agung Prasaja, Y., \& Rudi Supsiadji, M. (2009). Kemampuan Mahasiswa Mengaplikasikan Kritik Sastra Marxis Dalam Penelitian Sastra Interdisipliner. Parafrase.

Michael, T. (2018). Pergerakan Fakultas Hukum Dalam Dimensi tri Dharma (Modernitas Dan 
Ortodoks). Prosiding Call For Paper Dan Pengabdian Masyarakat Dalam Rangka Dies Natalis Ke-60 Universitas 17 Agustus 1945 Surabaya, 6.

Munirah. (2015). Pengembangan Keterampilan Menulis Paragraf. Depublish.

RAHYUDI, M. Z., Suhada, S., \& Widaningsih, I. (2019). KAJIAN PUBLIKASI ILMIAH DOSEN FEB UNPAD DALAM INDEKS SCOPUS, GOOGLE SCHOLAR DAN SINTA DIKTI. Kandaga- Media Publikasi Ilmiah Jabatan Fungsional Tenaga Kependidikan. https://doi.org/10.24198/kandaga.v1i1.20878

Santoso, H. (2015). Pencegahan Dan Penaggulangan Plagiarisme Dalam Penulisan Karya Ilmiah Di Lingkungan Perpustakaan Perguruan Tinggi. Univesitas Negeri Malang.

Setiawan, daryanto. (2017). Dampak Perkembangan Teknologi Informasi dan Komunikasi Terhadap Budaya Impact of Information Technology Development and Communication on. Jurnal Pendidikan. https://doi.org/10.1155/2015/146250

Sobari, T. (2018). PENERAPAN TEKNIK SIKLUS BELAJAR DALAM PEMBELAJARAN MENULIS LAPORAN ILMIAH BERBASIS VOKASIONAL. Sematik. https://doi.org/10.22460/semantik.vXiX.XXX

Sonata, D. L. (2015). METODE PENELITIAN HUKUM NORMATIF DAN EMPIRIS: KARAKTERISTIK KHAS DARI METODE MENELITI HUKUM. FIAT JUSTISIA. https://doi.org/10.25041/fiatjustisia.v8no1.283

Subagiyo, D. T. (1999). Resensi Buku: TEORI ETIKA TENTANG HUKUM ILEGAL. Perspektif. https://doi.org/10.30742/perspektif.v4i3.214

Suci, W. (2017). Identifikasi Dan Perumusan Masalah. Institut Agama Islam Negeri Metro.

\section{Ucapan Terima Kasih}

Ucapat terima kasih ditujukan kepada IKAPI Jawa Timur, Fakultas Hukum Universitas 17 Agustus 1945 Surabaya, R.A.De.Rozarie dan Universitas Agung Podomoro. 